\title{
Anthelminthic resistance of gastrointestinal nematodes in sheep to monepantel treatment in central region of Rio Grande do Sul, Brazil ${ }^{1}$
}

\author{
Fernanda Ramos ${ }^{2 *}$, Luiza P. Portella², Fernando de S. Rodrigues ${ }^{2}$, Caroline Z. \\ Reginato $^{2}$, Alfredo S. Cezar ${ }^{2,3}$, Luis A. Sangioni ${ }^{2}$ and Fernanda S.F. Vogel ${ }^{2}$
}

\begin{abstract}
Ramos F., Portella L.P., Rodrigues F.S., Reginato C.Z, Cezar A.S., Sangioni L.A. \& Vogel F.S. 2018. Anthelminthic resistance of gastrointestinal nematodes in sheep to monepantel treatment in central region of Rio Grande do Sul, Brazil. Pesquisa Veterinária Brasileira 38(1):48-52. Departamento de Medicina Veterinária Preventiva, Centro de Ciências Rurais, Universidade Federal de Santa Maria, Santa Maria, RS 97105-900, Brazil. E-mail: fernandaramos_7@yahoo.com.br

Given the numerous reports of anthelminthic resistance of sheep nematodes to different anthelmintic compounds, this study aimed to evaluate the resistance status of gastrointestinal nematodes from naturally infected sheep to monepantel in the state of Rio Grande do Sul. Four farms that present extensive raising system and absence of anthelmintic treatment for 60 days were selected for the study. Lambs that present counts of eggs per gram of feces (EPG) $\geq 200$ (sensitivity of $50 \mathrm{EPG}$ ) one day (D-1) before the treatment were select for the study and randomly separated into two groups, a control group and an experimental group treated with monepantel. Feces were collected 9 days after the treatment (D+9) for EPG counts and fecal culture. The monepantel was $100 \%$ effective only on 2 . The efficacy found on farm 1,3 , and 4 were $2.82 \%, 25.8 \%$, and $78.4 \%$, respectably. There were no viable larvae post-treatment at farm 2, but the genera Haemonchus, Trichostrongylus, Cooperia, and Strongyloides were resistant to it at the other farms. This study shows the presence of parasites resistant to the treatment with monepantel, pointing to the importance of monitoring its efficacy in sheep flocks of Rio Grande do Sul, Brazil.
\end{abstract}

INDEX TERMS: Anthelminthic resistance, gastrointestinal nematodes, sheep, monepantel, small ruminants, efficacy.

RESUMO-- [Resistência anti-helmíntica de nematódeos gastrointestinais de ovinos ao monepantel na região central do Rio Grande do Sul.] Devido aos numerosos relatos de resistência anti-helmíntica de nematódeos gastrintestinais de ovinos a diferentes compostos, este estudo objetivou avaliar o status da resistência de nematódeos gastrintestinais de ovinos naturalmente infectados ao monepantel no estado do Rio Grande do Sul. Quatro fazendas que apresentam sistema extensivo de criação e ausência de

\footnotetext{
${ }^{1}$ Received on December 20, 2016.

Accepted for publication on April 24, 2017.

${ }^{2}$ Departamento de Medicina Veterinária Preventiva (DMVP), Centro de Ciências Rurais (CCR), Universidade Federal de Santa Maria (UFSM), Bairro Camobi, Santa Maria, RS 97105-900, Brazil. *Corresponding author: fernandaramos_7@yahoo.com.br

${ }^{3}$ Programa de Pós-Graduação em Economia e Desenvolvimento, PNPD/ CAPES, UFSM, Santa Maria, RS, Brazil.
}

tratamento anti-helmíntico por 60 dias foram selecionados para o estudo. Animais que apresentassem as contagens de ovos por grama de fezes (OPG) $\geq 200$ (sensibilidade de 50 OPG) um dia (D-1) antes do tratamento foram selecionados para o estudo e separados em dois grupos, um grupo controle e um grupo experimental tratado com monepantel. Fezes foram coletadas nove dias após o tratamento $(\mathrm{D}+9)$ para realização do OPG e cultura fecal. 0 monepantel foi $100 \%$ eficaz apenas na propriedade 2 . A eficácia encontrada nas propriedades 1, 3 e 4 foi 2,82\%, 25,8\% e 78,4\%, respectivamente. Não houveram larvas viáveis após o tratamento nas propriedades 2, porém os gêneros Haemonchus, Trichostrongylus, Cooperia e Strongyloides demonstraram resistência a este nas demais propriedades. Este estudo mostra a presença de parasitas resistentes ao tratamento com monepantel, apontando para a importância de monitorar a sua eficácia em rebanhos de ovinos do Rio Grande do Sul, Brasil. 
TERMOS DE INDEXAÇÃO: Resistência anti-helmíntica, nematódeos gastrointestinais, ovinos, monepantel, pequenos ruminantes, eficácia.

\section{INTRODUCTION}

Among the diseases that affect small ruminants and result on decrease of productivity, parasitic infections caused by gastrointestinal nematodes are the major concern and obstacle faced by sheep farmers (Sczesny-Moraes et al. 2010). These parasites are associated with low body development, decrease in reproductive indexes and increase in the mortality rate in the flock.

This nematodes have developed resistance to the most common drugs available (benzimidazoles and macrocyclic lactones) which is recognized by the increase number of treatments needed to control them in small ruminants (Waller et al. 1996, Wolstenholme et al. 2004). Different studies have reported this lack of efficacy of different chemical groups, such reports include the studies of Cezar et al. (2010), Borges et al. (2015), and Bichuette et al. (2015) in the states of Rio Grande do Sul, Bahia, and São Paulo respectively.

In the year 2012, it was launched in Brazil the monepantel $\left(\right.$ Zolvix $\left.^{\circledR}\right)$, a molecule from amino-acetonitrile derivatives (AADs) chemical group. Despite this being a new molecule, in recent years, it has been notice parasitic resistance to this drug in several regions worldwide, including Brazil, (Scott et al. 2013, Mederos et al. 2014, Cintra et al. 2015, Van den Brom et al. 2015, Sales \& Love, 2016). In view of these reports, the present study aimed to evaluate the resistance status of gastrointestinal nematodes from naturally infected sheep to monepantel at different farms in the state of Rio Grande do Sul, Brazil.

\section{MATERIALS AND METHODS}

Farms and animals. This study was conducted at four farms located in the central region of Rio Grande do Sul. Farm 1 is located in the county of São Pedro do Sul ( $29^{\circ} 41^{\prime} 14,88^{\prime \prime}$ S, 54 $26^{\prime} 34,06^{\prime \prime}$ W), farm 2 in the county of São Gabriel (29 $59^{\prime} 12.5^{\prime \prime S} 54^{\circ} 25^{\prime} 47.6^{\prime \prime} \mathrm{W}$ ) and farms 3 and 4 in the county of São Martinho da Serra (29 $32^{\prime}$ $03.0^{\prime \prime}$, $53^{\circ} 51^{\prime} 24.04^{\prime \prime} \mathrm{W}$ ). The flocks were selected based on location and previous consent by farmers. All farms perform the breeding of cattle, horses, and sheep in an extensive raising system. The flock at farm 1 is composed of about 70 Texel- Ile de France cross breeding; at farm 2, the flock is composed of 300 Corriedale animals; farm 3 perform the breading of 1000 Texel and Suffolk sheep and at farm 4 the flock is composed of 250 Texel and Texel-Crioula cross breeding. All farms make the control of gastrointestinal parasites based on the result of efficacy tests witch are perform, at least, once a year. Results obtained through previous efficacy tests show that different anthelminthic compounds, such as ivermectin, doramectin, moxidectin, nitroxinil, disophenol, levamisole, albendazole, fenbendazole, and closantel are no longer effective for the control of the gastrointestinal nematodes on all these flocks, been the genera Haemonchus, Cooperia, and Trichostrongylus the most resistant to treatment with this drugs. Because of these resistance problems faced by all the farms, all of them already had a historic of monepantel $\left(\right.$ Zolvix $\left.^{\circledR}\right)$ use prior the study start.

At all farms, the treatment with anthelmintics is made in intervals of 30 days or less in the hot season (spring and summer), or when the animals shows clinical signs suggestive of parasitosis like apathy, weight loss, submandibular edema, paleness of mucous membranes, and an increase in the egg count per gram of feces (EPG). Selective treatment is performed only at farm 1 according with the famacha score (Molento et al. 2004).

Experimental groups and animals treatment. Fecal samples from naturally infected animals of both genders, which were approximately six months of age, were collected directly from the rectum of each animal at all farms. This animals have not received treatment with anthelminthic at least 60 days before the experimental period.

Fecal samples were collected one day before (D-1) and nine days (D+9) after treatment began, a practice adopted from previous studies conducted by Mederos et al. (2014) and Van den Brom et al. (2015). All samples were stored in individual plastic bags and refrigerated until processing, which was done immediately after all samples were collected.

The count of eggs per gram of feces (EPG) was performed using a modified McMaster technique, with a sensitivity of 50 EPG. Therefore, $2 \mathrm{~g}$ of homogenized feces were mixed with $28 \mathrm{ml}$ of a saturated solution, filtered, and transferred to a McMaster chamber for microscopic identification and for calculating the EPG. The animals that presented EPG $\geq 200$ on D-1 were selected and divided into two groups forming randomized blocks. At all farms, one control group was used to monitor the natural changes of EPG throughout the experimental period (Lyndal-Murphy et al. 2014, Neves et al. 2014) been 10 lambs on farm 1, 12 on farm 2, 17 on farm 3 and 10 on farm 4 . Other group treated with monepantel (Zolvix ${ }^{\circledR}$, Elanco) was formed with the same number of animals of the control group in each farm. These animals received this compound at its recommended dosage of $2.5 \mathrm{mg} / \mathrm{kg}$. All animals in the treated group were weighed, and they received monepantel orally with a syringe at a dose corresponding to their body weight, whereas the control group did not receive any type of treatment.

Ethics statement. The use of animals was approved by the Committee of Ethics in Animal Experimentation of the Federal University of Santa Maria, under protocol no. 8088190815.

Analysis and interpretation of results. As recommended by Neves et al. (2014), the pre and post-treatment EPG counts of the treated group were used to determine the efficacy of the monepantel treatment. For this purpose, we used the approach described by Torgerson et al. (2014), which is available at <http://shiny. math.uzh.ch/user/furrer/shinyas/shiny-eggCounts/>.

The efficacy of treatment, according to the genera of parasites identified in the culture of larvae from days D-1 and D+9, was determined using the formula: $\mathrm{PR}=100 \mathrm{x}$ (PERinitial - PERfinal/ PERinitial). In this equation, $\mathrm{PR}$ is the percentage of reduction by genera, PERinitial and PERfinal are the percentages of each gender one day before (D-1) and 9 days (D+9) after treatment began, respectively (Coles et al. 1992, 2006).

The status of anthelminthic resistance was interpreted according to the recommendations of Lyndal-Murphy et al. (2014), based on the guide of the World Association for the Advancement of Veterinary Parasitology (WAAVP) (Coles et al. 1992), which analyses the reduction percentage of the EPG and the upper limits (UL) and lower limits (LL) of the confidence interval (CI) to 95\%. Thus, the treatment was classified as: effective (percentage of reduction of EPG and UL 95\% equal or superior to 95\% and 95\% LL above 90\%); ineffective (percentage reduction and UL95\% below 95\% and LL95\% below 90\%); or inconclusive (none of the previous criteria filled).

\section{RESULTS}

The arithmetic means, maximum and minimum EPG, and EPG reduction percentage of groups treated with monepantel are present in Table 1. By the observation of this table, it is possible to check that there was no efficacy of 
Table 1. Results of eggs per gram of feces (EPG): arithmetic mean, maximum and minimum values of EPG and percentage reduction of EPG with upper and lower values of the confidence interval (CI) at 95\%, before (D-1) and after (D+9) monepantel (Zolvix $\left.{ }^{\circledR}\right)$ treatment, of lambs naturally infected from different farms in the state of Rio Grande do Sul, Brazil

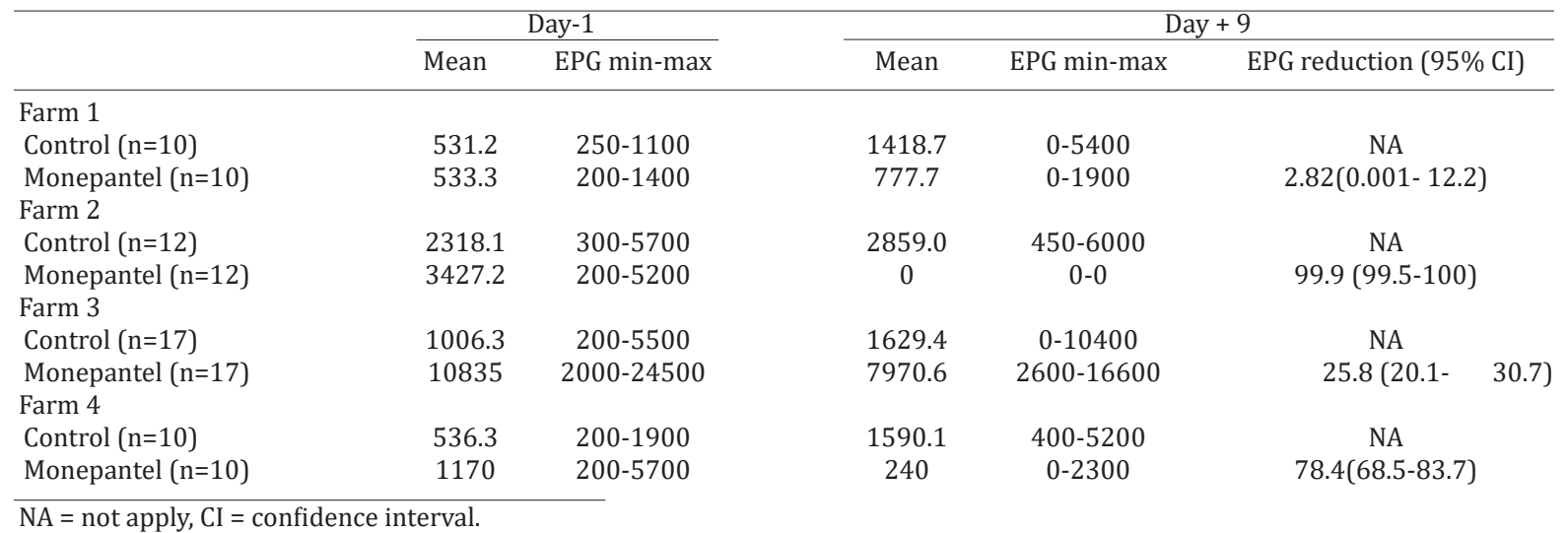

Table 2. Proportions of the genera of gastrointestinal nematodes identified before the treatment (D-1) with monepantel (Zolvix ${ }^{\circledR}$ ) in the feces of naturally infected lambs from four farms in the central region of the state of Rio Grande do Sul, Brazil

\begin{tabular}{|c|c|c|c|c|c|c|}
\hline \multirow[t]{2}{*}{ Farm } & \multicolumn{6}{|c|}{ Genera of the gastrointestinal nematodes found one day before the treatments (\%) } \\
\hline & Cooperia spp. & Haemonchus spp. & Trichostrongylus spp. & Ostertagia spp. & Oesophagostomum spp. & Strongyloides spp. \\
\hline 1 & 25.5 & 54.9 & 9.8 & & 9.8 & \\
\hline 2 & 18 & 72 & 8 & 2 & & \\
\hline 3 & 16 & 46 & 38 & & & \\
\hline 4 & & 32 & 54 & 2 & & \\
\hline
\end{tabular}

Table 3. Proportions of the genera identified after the treatment $(D+9)$ with monepantel $\left(Z o l v i x^{\circledR}\right)$ in the feces of naturally infected lambs from four farms in the state of Rio Grande do Sul and respective efficacy of the treatment for each genera

\begin{tabular}{|c|c|c|c|c|c|c|}
\hline \multirow[t]{2}{*}{ Farm } & \multicolumn{6}{|c|}{ Genera of the gastrointestinal nematodes found nine days after the treatments (\%) and efficacy of the treatment per genus } \\
\hline & Cooperia spp. & Haemonchus spp. & Trichostrongylus spp. & Ostertagia spp. & Oesophagostomum spp. & Strongyloides spp. \\
\hline 1 & 19.6 (23.1\%) & $23.4(57.1 \%)$ & $8(18.3 \%)$ & & $0(100 \%)$ & $49(0 \%)$ \\
\hline 2 & 0 (100\%) & 0 (100\%) & $0(100 \%)$ & $0(100 \%)$ & & \\
\hline 3 & $8(50 \%)$ & 15 (30.4\%) & $77(0 \%)$ & & & \\
\hline 4 & $14(0 \%)$ & $62(0 \%)$ & $24(55.50 \%)$ & $0(100 \%)$ & & \\
\hline
\end{tabular}

the treatment with monepantel $\left(\right.$ Zolvix $\left.^{\circledR}\right)$ at tree of the four $(3 / 4)$ farms studied. It is also possible to see that there was a natural increase of EPG of the control groups at all farms, showing that there was no environmental factor associated to the decrease of EPG values in the treated groups during the experimental period. The genera of parasites identified before the treatment of the animals (D-1) are present in Table 2. Nine days after the use of this compound (D+9), there was no significative change in the proportion of the genera of nematodes identified in the control group of all farms (data not show). However, some changes appear in the treated groups, pointing to different levels of resistance of the nematode population present at each farm (Table 3).

It was possible to ascertain on $\mathrm{D}+9$ that some animals of the treated groups at all farms present suggestive clinical signs of persistent infection by gastrointestinal nematodes. Those signs include apathy, lethargy, and anemia of mucous membranes, pointing to a treatment inefficacy.

\section{DISCUSSION}

The resistance of gastrointestinal nematodes in small ruminants to anthelmintic treatment can be observed in several regions of the world, including in Brazil (Duarte et al. 2012, McMahon et al. 2013, Martínez-Valladares et al. 2015). Little et al. (2010) have argued that the treatment of the animals with effective anthelminthic therapies, used in a strategic way and in conjunction with other control practices, is the best option for producers. However, studies have shown that parasite resistance has gradually increased. The continuing lack of information concerning the treatment of parasite-infected animals has led to the inefficacy of the compounds belonging to the three major classes of broad-spectrum anthelminthic treatments (Sutherland et al. 2008). As a reflex of this farm and flock owners have suffered serious consequences, including, in some cases, the dissolution of their flocks and properties (Blake \& Coles 2007).

The drug monepantel belongs to a group of amino-acetonitrile derivatives (AADs), which represent a new class of anthelminthic therapy. This compound was launched in the year of 2009, reaching the Brazilian market in 2012, and consequently providing a new alternative treatment for farmers (Hosking et al. 2008). However, similar to the studies of Mederos et al. (2014) and Scott et al. (2013) in Uruguay and New Zealand respectively, the parasitic popu- 
lations identified in this studied showed resistance to monepantel only four years after the product became available in the market.

After seventeen applications of this anthelminthic treatment over the course of two years, Scott et al. (2013) observed strains of Teladorsagia circumcincta and Trichostrongylus colubriformis resistant to the treatment with monepantel in goats and sheep. However, the results obtained in our study suggest that the appearance of resistant strains can occurs after fewer generations than observed in the study performed by Scott et al. (2013). The nematode populations resistant to monepantel $\left(\right.$ Zolvix $\left.^{\circledR}\right)$ treatment observed in this study, were detected after only four, tree and five applications of this principle in its therapeutic dosage, at farms 1,3 , and 4, respectively. These data are similar to those obtained by Cintra et al. (2015), who found the selection of strains of $T$. colubriformis following the use of monepantel in a non-suppressive treatment and involving the selective treatment of animals over a period of just five months.

One of the reasons for the apparent resistance of these gastrointestinal nematodes populations to monepantel, may be due to the low presence of larvae in refuge, or in other words, the larvae that had no exposure to the anthelminthic treatments. The lack of selective treatments, presence of few animals naturally resistant to parasitism, and the treatments that were made in a suppressive form, could explain the anthelmintic resistance observed at farms 1,3 , and 4 (Kenyon et al. 2009). This practices leads to rapid selection of the nematode populations because, even if a small parcel survive an effective treatment, this will be the unique stock of larvae available for the reinfection of flock (Busin et al. 2013). However, Bartley et al. (2015) argue that aspects such as prior exposure to anthelminthic compounds; inherent sensitivity to compounds in functional dose-limiting species; the initial frequency of potential genes for resistance within a population; the nature of the genetic heritage (dominant/recessive), and the impact of non-specific mechanisms of resistance on the survivability of certain isolated individuals, hinder the estimates of what may occur within certain parasitic populations after the anthelminthic treatment is administered to the animals.

Combinations of anthelmintics compounds could restore the efficacy of the treatments on the studied farms, as was demonstrated in a study conducted by Cezar et al. (2011). However, similar to conventional treatments, the long-term use of such combinations can become ineffective as the nematode populations are resistant to all classes of available drugs (Cezar et al. 2010). Regardless, alternative methods of control must be integrated to productive systems. These new methods should be more effective than combined allopathic treatments and help to slow the development of resistance (Waller 2006, Torres-Acosta \& Hoste 2008).

The results of this study, summed up to the historic anthelminthic resistance to other principles at all farms, confirm the need for the establishment of control programs based on clinical and epidemiological criteria, and the need for frequent monitoring of the efficacy of such tre- atments (Cezar et al. 2010). In this context, according to the recommendations of Waller (2006) and Molento et al. (2013), alternative methods that lead to a reduction of the frequency of treatments should be adopted. Such methods could include the selection of less susceptible animals and the alternation between agricultural and livestock farming activities. This may slow down the development of parasite resistance and increase the lamb's development.

\section{CONCLUSIONS}

The resistance of gastrointestinal nematodes in sheep has gradually worsened after the compound monepantel launch on the Brazilian market. The compound has been shown to be ineffective at three of the four studied farms in the state of Rio Grande do Sul.

Studies which aim to understand the molecular mechanisms for the development of resistant parasite populations to the monepantel treatment are necessary, in order to develop strategies to delay the appearance of new cases of resistance to this compound and increase its efficiency.

Acknowledgments.- The authors are grateful for the availability and collaboration of producers and their employees to carry out this work.

Conflict of interest.- The authors of this manuscript have no financial or personal relationships with other people or organizations that could inappropriately influence or bias the content of the paper.

\section{REFERENCES}

Bartley D.J., Devin L., Nath M. \& Morrisona A.A. 2015. Selection and characterisation of monepantel resistance in Teladorsagia circumcincta isolates. Int. J. Parasitol. Drugs Drug Resist. 5(2):69-76.

Blake B. \& Coles G.C. 2007. Flock cull due to anthelmintic-resistant nematodes. Vet. Rec. 161:36.

Borges S.L., Oliveira A.A., Mendonça L.R., Lambert S.M., Viana J.M., Nishi S.M., Julião F.S. \& Almeida M.A.O. 2015. Anthelminthic resistance in goat flocks in biomes Caatinga and Atlantic Forest. Pesq. Vet. Bras. 35:643-648.

Bichuette M.A., Lopes W.D.Z., Gomes L.V.C., Felippelli G., Crosses B.C., Maciel W.G., Teixeira W.F.P., Buzzulini C., Prando L., Soares V.E., Fields G.P. \& Costa A.J.C. 2015. Susceptibility of helminth species parasites of sheep and goats to different chemical compounds in Brazil. Small Rumin. Res. 133:93-101.

Busin V., Kenyon F., Laing N., Denwood M.J., McBean D., Sargison N.D. \& Ellis K. 2013. Addressing sustainable sheep farming: application of the targeted selective treatment approach is anthelmintic online to commercial farm use. Small Rumin. Res. 110:110-103.

Cezar A.S., Toscan G., Camillo G., Sangioni L.A., Ribas H.O. \& Vogel F.S.F. 2010. Multiple resistance of gastrointestinal nematodes to nine different drugs in the sheep flock in southern Brazil. Vet. Parasitol. 173:157160.

Cezar A.S., Ribas H.O., Pivoto F.L., Sangioni L.A. \& Vogel F.S.F. 2011. Combination of drugs-parasitic as an alternative for the control of gastrointestinal nematodes multidrug resistant in sheep. Pesq. Vet. Bras. 31:151157.

Cintra M.C.R., Teixeira V.N., Birth L.V. \& Sotomaior C.S. 2015. Lack of efficacy of monepantel against Trichostrongylus colubriformis in sheep in Brazil. Vet. Parasitol. 216:4-6.

Coles G.C., Bauer C., Borgsteede F.H., Geerts S., Klei T.R., Taylor M.A. \& Waller P.J. 1992. World Association for the Advancement of Veterinary Parasitology (WAAVP) methods for the detection of anthelmintic resistance in nematodes of veterinary importance. Vet. Parasitol. 44:35-44.

Coles G.C., Jackson F., Pomroy W.E., Prichard R.K., Samson-Himmelstjerna G.V., Silvestre A., Taylor M.A. \& Vercruysse J. 2006. The detection of an- 
thelmintic resistance in nematodes of veterinary importance. Vet. Parasitol. 136:167-185.

Duarte E.R., Silva R.B., Vasconcelos V.O., Nogueira F.A. \& Oliveira N.J.F. 2012. Control Diagnostics and sensitivity profile of nematodes of sheep to albendazole and to levamisole in northern Minas Gerais. Pesq. Vet. Bras. 32:147-152.

Hosking B.C., Stein A.P., Mosimann D., Seewald W., Strehlau G. \& Kaminsky R. 2008. Dose determination studies is monepantel, an amino-acetonitrile derivative, against fourth stage gastro-intestinal nematode larvae infecting sheep brewery. Vet. Parasitol. 157:72-80.

Kenyon F., Greer A.W., Coles G.C., Cringoli G., Papadopoulos E., Cabaret J., Berrag B., Varady M., Van Wyk J.A., Thomas E., Vercruysse J. \& Jackson F. 2009. The scroll of targeted selective treatments in the development of refuge-based approaches to the control of gastrointestinal nematodes of small ruminants. Vet. Parasitol. 164:3-11.

Little P.R., Hodge A. ,Watson T.G., Seed J.A. \& Maeder S.J. 2010. Field efficacy and safety of an oral formulation of the novel combination anthelmintic, derquantel/abamectin, in sheep in New Zealand. N Z Vet. J. 58(3):121-129.

Lyndal-Murphy M., Swain A.J. \& Pepper P.M. 2014. Methods to determine resistance to larval development anthelmintics when continuing it repeats. Vet. Parasitol. 199:191-200.

McMahon C., Bartley D.J., Edgar H.W.J., Ellison S.E., Burley J.P., Malone F.E., Hanna R.E.B., Brennan G.P. \& Fairweather I. 2013. Anthelmintic resistance in Northern Ireland (I): Studies of resistance in porcine Ovine gastrointestinal nematodes, determined through fecal egg count reduction testing. Vet. Parasitol. 195:122-130.

Martínez-Valladares M., Geurden T., Bartram D.J., Martínez-Pérez J.M., Robles-Pérez D., Bohórquez A., Florezd E., Meana A. \& Rojo-Vázqueza F.A. 2015. Resistance of gastrointestinal nematodes to the most commonly used anthelmintics in sheep, cattle and horses in Spain. Vet. Parasitol. 211(3/4):228-233.

Mederos A.E., Banchero G.E. \& Ramos Z. 2014. First report of monepantel Haemonchus contortus resistance on sheep farms in Uruguay. Parasit. Vectors 7:598

Molento M.B., Tasca C., Gallo A., Ferreira M., Bononi R. \& Stecca E. 2004. Famacha guide as an individual clinic parameter for Haemonchus contortus infection in small ruminants. Ciênc. Rural 34:1139-1145.
Molento M.B., Veríssimo C.J., Amarante A.T., van Wyk J.A., Chagas A.C.S., de Araújo J.V. \& Borges F.A. 2013. Alternativas para o controle de nematoides gastrintestinais de pequenos ruminantes. Arq. Inst. Biol. 80(2):253263.

Neves J.H.D., Carvalho N., Rinaldi L., Cringoli G. \& Amarante A.F.T. 2014. Diagnosis of anthelmintic resistance in cattle in Brazil: a comparison of different methodologies. Vet. Parasitol. 206:216-226.

Sales N. \& Love S. 2016. Resistance of Haemonchus sp. to monepantel and reduced efficacy of a derquantel / abamectin combination confirmed in sheep in NSW, Australia. Vet. Parasitol. 228:193-196.

Scott I., Pomroy W.E., Kenyon P.R., Smith G., Adlington B. \& Moss A. 2013. Lack of efficacy of monepantel against Teladorsagia circumcincta and Trichostrongylus colubriformis. Vet. Parasitol. 198:166-171.

Sczesny-Moraes E.A., Bianchin I., Silva K.F., Catto J.B., Honer M.R. \& Paiva F. 2010. Resistência anti-helmíntica de nematopides gastrointestinais em ovinos, Mato Grosso do Sul. Pesq. Vet. Bras. 30(3):229-236.

Sutherland I.A., Damsteegt A., Miller C.M. \& Leathwick D.M. 2008. Multiple species of nematodes resistant to ivermectin and the benzimidazole levamisole combination on the sheep farm in New Zealand. N.Z. Vet. J. 56:67-70.

Torgerson P.R., Paul M. \& Furrer R. 2014. Evaluating fecal egg count reduction using a specifically designed package "eggCounts" in R and the user friendly web interface. Int. J. Serology 44:299-303.

Torres-Acosta J.F.J. \& Assemblage H. 2008. Alternative or improved methods to Limit gastro-intestinal parasitism in sheep and goats. Small Rumin. Res. 77:159-173.

Van den Brom R., Moll L., Kappert C. \& Vellema P. 2015. Haemonchus contortus resistance to monepantel in sheep. Vet. Parasitol. 209(3-4):27880

Waller P.J. 2006. Firmo nematode parasites control strategies for ruminant livestock by management and biological control. Anim. Feed Sci. Technol. 126:277-289.

Waller P.J., Echevarria F., Eddi C., Maciel S., Nari A. \& Hansen J.W. 1996. The prevalence of anthelmintic resistance in nematode parasites of sheep in Southern Latin America: General overview.Vet Parasitol. 62:181-187.

Wolstenholme A.J., Fairweather I., Prichard R., Von Samson-Himmelstjerna G. \& Sangster N.C. 2004. Drug resistance in veterinary helminthes. Trends Parasitol. 20:469-476. 